Article

\title{
Capillary Electrophoresis-Mass Spectrometry with Multisegment Injection and In-Capillary Preconcentration for High-Throughput and Sensitive Determination of Therapeutic Decapeptide Triptorelin in Pharmaceutical and Biological Matrices
}

\author{
Juraj Piešł anský ${ }^{1,2}{ }^{\circledR}$, Ivana Čižmárová ${ }^{1}$, Ondrej Štefánik ${ }^{1}$, Michaela Matušková ${ }^{1}$, Andrea Horniaková ${ }^{1}$, \\ Petra Majerová ${ }^{2}$ and Peter Mikuš ${ }^{1,3, *[1}$
}

1 Department of Pharmaceutical Analysis and Nuclear Pharmacy, Faculty of Pharmacy, Comenius University in Bratislava, Odbojarov 10, SK-832 32 Bratislava, Slovakia; piestansky@fpharm.uniba.sk (J.P.); svorcova7@uniba.sk (I.Č.); stefanik38@uniba.sk (O.Š.); matuskova53@uniba.sk (M.M.); horniakova24@uniba.sk (A.H.)

2 Institute of Neuroimmunology, Slovak Academy of Science, Dubravska cesta 9, SK-845 10 Bratislava, Slovakia; petra.majerova@savba.sk

check for
updates

Citation: Piešt'anský, J.; Čižmárová, I.; Štefánik, O.; Matušková, M.; Horniaková, A.; Majerová, P.; Mikuš, P. Capillary Electrophoresis-Mass Spectrometry with Multisegment Injection and In-Capillary Preconcentration for High-Throughput and Sensitive Determination of Therapeutic Decapeptide Triptorelin in Pharmaceutical and Biological Matrices. Biomedicines 2021, 9, 1488. https: / / doi.org/10.3390/

biomedicines 9101488

Academic Editor: Giuliana Cangemi

Received: 1 October 2021

Accepted: 13 October 2021

Published: 16 October 2021

Publisher's Note: MDPI stays neutral with regard to jurisdictional claims in published maps and institutional affiliations.

Copyright: (C) 2021 by the authors Licensee MDPI, Basel, Switzerland. This article is an open access article distributed under the terms and conditions of the Creative Commons Attribution (CC BY) license (https:/ / creativecommons.org/licenses/by/ $4.0 /)$.
3 Toxicological and Antidoping Center, Faculty of Pharmacy, Comenius University in Bratislava, Odbojarov 10, SK-832 32 Bratislava, Slovakia

* Correspondence: mikus@fpharm.uniba.sk; Tel.: +421-2-50-117-243

\begin{abstract}
A capillary electrophoresis-tandem mass spectrometry method with a multisegment injection and an in-capillary field-enhanced sample stacking for determination of therapeutic peptide triptorelin in pharmaceutical and biological matrices was developed. The CE separation conditions were optimized in order to obtain maximal separation efficiency, analytical signal intensity and stability, and minimal adsorption of the analyzed peptide onto the capillary wall (1 M formic acid$\mathrm{HFo}, \mathrm{pH}$ 1.88). The implementation of the field-enhanced sample injection into CE improved the value of limit of detection 50 times while the multisegment injection increased the sample throughput three times in comparison to a conventional CE approach. The proposed method was characterized by favorable performance parameters, such as linearity $\left(\mathrm{r}^{2} \geq 0.99\right)$, limit of detection $\left(5 \mathrm{ng} \mathrm{mL} \mathrm{m}^{-1}\right.$ in water matrix, $25 \mathrm{ng} \mathrm{mL}^{-1}$ in plasma matrix), precision (relative standard deviation, 1.5-9.4\% for intraday and $2.3-11.9 \%$ for interday reproducibility), or accuracy (relative errors in the range of $80-109 \%$ ). The FDA-validated method was successfully applied to the analysis of triptorelin in the commercial drug Diphereline ${ }^{\circledR} 0.1 \mathrm{mg}$ (powder for injection) and in spiked human plasma samples. Favorable performance parameters along with proven application potentialities indicate the usefulness of the proposed method for its routine use in drug quality control laboratories and for clinical analysis, such as determination of triptorelin levels in plasma (for pharmacokinetic study).
\end{abstract}

Keywords: capillary electrophoresis; tandem mass spectrometry; triptorelin peptide drug; fieldenhanced sample injection; multisegment injection; pharmaceutical and biological samples

\section{Introduction}

Triptorelin is a synthetic decapeptide (pGlu-His-Trp-Ser-Tyr-D-Trp-Leu-Arg-Pro-Gly$\mathrm{NH} 2$ ) used in the treatment of breast, endometrial and prostate cancer, and male hypersexuality with severe sexual deviation. The peptide is also used "off-label" as a puberty blocker in patients with gender dysphoria [1]. Triptorelin represents a synthetic analogue of gonadotropin-releasing hormone $(\mathrm{GnRH})$ and is a modulator of the GnRH receptor where it can act as an agonist or antagonist. It is able to increase the circulating levels of luteinizing hormone, follicle stimulating hormone and testosterone. The stimulation of secretion of the above-mentioned hormones is responsible for growth-promotion which 
can lead to improvement of sport performances. According to these facts, triptorelin and other GnRH analogues were included in the Prohibited List of the World Anti-Doping Agency (WADA) and are summarized in Section S2 "Peptide hormones, growth factors, related substances, and mimetics" [2]. Therefore, there are demands for precise, accurate, robust, and sensitive analytical methods capable to identify and quantify triptorelin in pharmaceutical and biological matrices.

Recent approaches for drug analysis are mainly based on liquid chromatography (LC) hyphenated with conventional (UV, DAD, fluorescence) or advanced (mass spectrometry, MS) detection techniques [3-6]. The LC strategies are considered as a gold standard for pharmaceutical and biomedical analyses. Although LC represents a dominating technique also for quantitative analysis of peptides and peptide or protein-based drugs [7-10], capillary electrophoresis (CE) is traditionally a powerful alternative to LC in analysis of biomolecules. This is due to several inherent benefits of CE including enhanced selectivity for charged substances, high speed of analysis, high separation efficiency and low consumption of the sample. Analogically to LC-MS, the coupling of CE with MS (CE-MS) significantly spreads possibilities in the analysis of complex biological mixtures [11,12].

There are only few papers which deal with the analysis of triptorelin by CE approaches. Those papers are focused on investigation of migration behavior of therapeutic peptide hormones [13,14], development of a CE-MS method for analysis of therapeutic peptide hormones including triptorelin [15], comparison of sheath-less and sheath-flow electrospray interfaces for CE-MS analysis of peptides [16], and development of a CE-UV method for study of the binding constants between an anionic polydispersed polymer and triptorelin relevant for development of the peptide drug delivery systems and their quality control [17]. All of these studies, however, were performed only with the use of model samples and peptide standards. The CE-MS methods for triptorelin determination [15] and [16] were characterized by the limit of detection (LOD) at 3.65 and $2.25 \mu \mathrm{g} \mathrm{mL} \mathrm{L}^{-1}$ levels and the reproducibility of the measurements (expressed as \%RSD of peak area) at 15 and 33\% levels, respectively. However, none of the previously published methods involved a complex validation protocol or application on real samples.

An aim of the present study is to develop an effective and reliable CE-MS method for determination of triptorelin in real pharmaceutical and biological matrices. The proposed method should combine a simple in-capillary sample stacking procedure based on fieldenhanced sample injection (FESI) with a multisegment injection (MSI) approach in order to achieve considerable enhancement in performance parameters. Optimization of the separation of electrolyte composition for preventing adsorption of the biomolecule onto capillary wall is an integral part of the method development as well. Improvements in sensitivity, reproducibility, accuracy, and sample throughput are highly demanded in routine control laboratories where the proposed method should be implemented.

\section{Materials and Methods}

\subsection{Chemicals and Samples}

LC-MS grade chemicals used for the preparation of the electrolyte solutions and sheath liquid were purchased from Merck (Darmstadt, Germany), Sigma Aldrich (Steinheim, Germany), and Fluka (Buchs, Switzerland). Demineralized water, prepared by a water purification system Millipore Simplicity 185 (UV) (Millipore, Molsheim, France), was used as a solvent for the electrolytes, sheath liquid, and samples. The electrolyte systems were filtered before use through disposable membrane filters $(0.22 \mu \mathrm{m}$ pore size Millipore) and were stored in the fridge before analysis. Triptorelin acetate was purchased from Caslo (Lyngby, Denmark) and the commercial drug Diphereline ${ }^{\circledR} 0.1 \mathrm{mg}$ (containing triptorelin acetate powder for injection) was obtained from Ipsen Pharma Biotech (Signes, France).

\subsection{Instrumentation}

The electrophoretic measurements were performed with the use of an Agilent 7100 capillary electrophoresis system (Agilent Technologies, Santa Clara, CA, USA). For CE- 
MS experiments an Agilent 6410 Series Triple Quadrupole tandem mass spectrometer (Agilent Technologies, Santa Clara, CA, USA) was coupled to the CE system by a commercial electrospray (ESI) sheath liquid interface equipped with a stainless-steel needle. The separation was performed in a $90 \mathrm{~cm} \times 50 \mu \mathrm{m}$ ID bare fused silica capillary (MicroSolv Technology Corporation, Eatontown, NJ, USA). The samples were injected hydrodynamically at 50 mbar for $20 \mathrm{~s}$, unless otherwise stated. Experiments were conducted under normal polarity, applying voltage of $25 \mathrm{kV}$ during electrophoretic separations. For CE-MS measurements the sheath liquid was delivered by an Agilent 1100 series isocratic LC pump

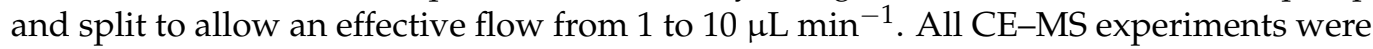
performed in positive ion mode and in the Multiple Reaction Monitoring (MRM) mode. The dwell time was $200 \mathrm{~ms}$.

\subsection{Capillary Treatment}

Prior to use, a new separation capillary was activated and conditioned flushing it for $15 \mathrm{~min}$ with aqueous $1 \mathrm{M} \mathrm{NaOH}$, followed by $15 \mathrm{~min}$ with demineralized water and $10 \mathrm{~min}$ with background electrolyte (BGE). All capillary rinses were performed at the pressure 950 mbar. Before each injection the capillary was re-equilibrated by applying a negative voltage of $-20 \mathrm{kV}$ for $30 \mathrm{~s}$ and flushing it with BGE for $2 \mathrm{~min}$. At the end of each day, the capillary was rinsed with aqueous $0.1 \mathrm{M} \mathrm{NaOH}$ and demineralized water for $20 \mathrm{~min}$, with BGE for 10 min and stored in BGE overnight.

\subsection{Field-Enhanced Sample Injection (FESI) and Multisegment Injection (MSI)}

The FESI procedure consisted of the following steps: first, the capillary was filled with the BGE. Then a short plug of deionized water was hydrodynamically injected at 50 mbar for $5 \mathrm{~s}$. Finally, a triptorelin sample was injected electrokinetically by applying a voltage of $10 \mathrm{kV}$ for $20 \mathrm{~s}$.

The MSI was performed in CE according to following procedure: first, the capillary was preconditioned for $2 \mathrm{~min}$ by flushing with BGE. Then, a short plug of deionized water was hydrodynamically injected at 50 mbar for $5 \mathrm{~s}$ and the triptorelin sample was injected electrokinetically by applying a voltage of $10 \mathrm{kV}$ for $20 \mathrm{~s}$. After that, a BGE spacer plug was introduced at 50 mbar for $100 \mathrm{~s}$. The procedure with sample and BGE spacer plug introduction was repeated three times. The experiments were conducted under normal polarity, applying voltage of $25 \mathrm{kV}$ during electrophoretic separations.

\subsection{Procedures for Sample and Standard Solution Preparation}

A stock solution containing $1 \mathrm{mg} \mathrm{mL}^{-1}$ triptorelin was prepared by dissolving an appropriate amount of the triptorelin acetate standard in BGE. The working solutions of triptorelin were made by a proper dilution of the stock solution with demineralized water or plasma in glass vials. The concentration levels of triptorelin in the injected calibration solutions were in the range of $0.01-10 \mu \mathrm{g} \mathrm{mL}^{-1}\left(0.01,0.05,0.1,0.5,1,2,5\right.$, and $\left.10 \mu \mathrm{g} \mathrm{mL}^{-1}\right)$ for water and $0.05-10 \mu \mathrm{g} \mathrm{mL}^{-1}\left(0.05,0.1,0.5,1,2,5\right.$, and $\left.10 \mu \mathrm{g} \mathrm{mL}^{-1}\right)$ for plasma. The pooled plasma samples were prepared by mixing a $100 \mu \mathrm{L}$ volume of plasma from each individual plasma samples obtained from 5 healthy volunteers. The quality control $(\mathrm{QC})$ plasma samples were prepared by spiking the pooled plasma samples (before protein precipitation) with the standard solution at three concentration levels: $0.05 \mu \mathrm{g} \mathrm{mL}{ }^{-1}$ (low QC), $1 \mu \mathrm{g} \mathrm{mL}^{-1}$ (medium QC), and $10 \mu \mathrm{g} \mathrm{mL}^{-1}$ (high QC). A $10 \mu \mathrm{L}$ aliquot of each QC sample was transferred into the Eppendorf tube and $30 \mu \mathrm{L}$ of acetonitrile with $0.1 \%$ formic acid (HFo) was added. After $10 \mathrm{~min}$ at laboratory temperature, the sample was centrifuged at $13,000 \times g$ for $10 \mathrm{~min}$. The supernatant was then transferred to a CE vial and directly injected into the $\mathrm{CE}$ analyzer.

The pharmaceutical sample of triptorelin, Diphereline ${ }^{\circledR} 0.1 \mathrm{mg}$ (powder for injections), was prepared by reconstitution of the powder in the original ampoule with $1 \mathrm{~mL}$ of water for injections. The ampoule was shaken gently to form a homogenous solution. The stock 
sample solution was further 100-times diluted with demineralized water in a glass vial. The diluted sample was directly injected into the CE apparatus.

The plasma samples were obtained from five healthy volunteers. The study was conducted according to the guidelines of the Declaration of Helsinki and approved by the Ethical Committee of National Oncology Institute, Bratislava, Slovakia (protocol IZLO-1). The blood samples were collected in the morning in test tubes containing EDTA. Plasma was obtained by centrifugation $(12,000 \times g, 10 \mathrm{~min})$ within $30 \mathrm{~min}$ of sample collection. The samples were aliquoted and stored at $-20^{\circ} \mathrm{C}$ until further analysis. Before analysis, the plasma samples were left to thaw at $4{ }^{\circ} \mathrm{C}$, and then $10 \mu \mathrm{L}$ of each sample was transferred to an Eppendorf tube and $30 \mu \mathrm{L}$ of acetonitrile with $0.1 \%$ HFo was added to precipitate proteins. After $20 \mathrm{~min}$ at laboratory temperature, the samples were centrifuged at $13,000 \times g$ for $10 \mathrm{~min}$. The supernatant was then transferred to a $\mathrm{CE}$ vial and directly analyzed by the CE-MS method. Three consecutive injections of the sample were realized.

\section{Results and Discussion}

\subsection{Optimization of CZE Separation}

In general, the separation of various substances by the CE-MS combination demands volatile electrolytes with low ion strength [18]. Therefore, organic acids with low molecular weight, such as formic acid (HFo) or acetic acid (HAc), and their ammonia salts were tested as the BGE components. Analysis of therapeutic peptides by CE-MS is typically performed under acidic conditions [19] and this strategy was used also in our work. The effect of the BGE composition on the triptorelin signal intensity and stability is presented in Table 1. Higher concentrations of HFo were favorable for higher separation efficiency (expressed as number of theoretical plates, $\mathrm{N}$ ) although slight increase of the migration time was also observed. On the other hand, the peak tailing occurred when the HFo solutions with lower concentrations were used for the separation. This may be caused by an unwanted adsorption of the peptide on the inner walls of the bare fused silica capillary. In the case of peptide separations, increased ion strengths are typically used to suppress adsorption [20-22]. In our work we demonstrated a $1000 \mathrm{mM}$ HFo solution was effective for minimizing triptorelin adsorption (peak tailing was negligible). The improvement of peak shape was reflected also in an enhancement of peak area reproducibility (which was lower than 5\% with a $1000 \mathrm{mM}$ HFo solution). With respect to a maximum separation efficiency and reproducibility and a minimum adsorption of the analyte, a $1000 \mathrm{mM} \mathrm{HFo}$ solution ( $\mathrm{pH}$ 1.88) was finally chosen as an optimum BGE. Under this acidic $\mathrm{pH}$ value, the silanol groups of the separation capillary wall are uncharged, and the electroosmotic flow (EOF) is eliminated. By eliminating EOF, only cations could migrate towards to detector. Thus, CE can serve as an effective ionic filter for anionic and neutral sample matrix constituents (i.e., prevent their detection interferences with the cationic analyte). Moreover, at the acid $\mathrm{pH}$, the surface of the inner capillary wall is uncharged which is favorable for preventing adsorption of the analyte on it.

Table 1. Optimization of the background electrolyte (BGE) composition of the CE-MS method for triptorelin determination.

\begin{tabular}{|c|c|c|c|c|c|c|}
\hline BGE & $\mathrm{pH}$ & $\underset{(\mathrm{min})}{t_{\mathrm{m}}}$ & $\begin{array}{c}\mathrm{RSD}_{\mathrm{tm}} \\
(\%)\end{array}$ & $\begin{array}{l}\text { RSD }_{\text {area }} \\
(\%)\end{array}$ & $\mathbf{N}$ & $\mathrm{S} / \mathbf{N}$ \\
\hline $10 \mathrm{mM}$ HFo & 2.91 & 9.47 & 1.8 & 6.4 & 14,441 & 33.3 \\
\hline $20 \mathrm{mM}$ HFo & 2.75 & 9.53 & 0.9 & 7.0 & 21,197 & 54.1 \\
\hline $50 \mathrm{mM}$ HFo & 2.54 & 9.66 & 2.5 & 6.2 & 20,041 & 55.8 \\
\hline $50 \mathrm{mM} \mathrm{HFo}+50 \mathrm{mM}$ HAc & 2.85 & 10.42 & 0.5 & 20.7 & 24,552 & 52.5 \\
\hline 1000 mM HFo & 1.88 & 10.53 & 1.3 & 4.6 & 27,683 & 52.6 \\
\hline $10 \mathrm{mM} \mathrm{NH}_{4} \mathrm{Fo}+20 \mathrm{mM} \mathrm{HFo}$ & 3.20 & 8.30 & 1.3 & 8.8 & 19,794 & 51.7 \\
\hline
\end{tabular}




\subsection{Optimization of MS Detection}

\subsubsection{Electrospray Ionization (ESI) Step}

The electrospray ionization (ESI) and MS detection steps were optimized to ensure proper identification and quantification of triptorelin. In the case of a commercial coaxial sheath-flow ESI interface, the composition of sheath liquid and its flow rate are the crucial parameters.

The sheath liquid is responsible for appropriate ionization of the analytes and for establishing the required electrical contact between the liquid inside the separation $\mathrm{CE}$ capillary and the metal tube acting as electrode [23]. It is typically composed of an organic solvent mixed with a certain percentage of water and small amounts of volatile acid or base additives providing an enhancement of ESI efficiency. Here, two types of sheath liquids were investigated: (i) methanol $/ 0.1 \%$ HFo water solution $(50 / 50, v / v)$, and (ii) methanol $/ 5 \mathrm{mM}$ ammonium acetate $\left(\mathrm{NH}_{4} \mathrm{Ac}\right)$ water solution $(50 / 50, v / v)$. The sheath liquid based on a $\mathrm{NH}_{4} \mathrm{Ac}$ additive was characterized by a sufficient stability of the electric current generated in the ionization chamber of the MS and an enhanced signal intensity of triptorelin, (with a 1.5-times higher $\mathrm{S} / \mathrm{N}$ ratio) in comparison to this one based on a HFo additive. These findings were in a good agreement with our previous paper dealing with CE-MS analysis of immunogenic peptides [10]. Hence, the mixture of methanol with $5 \mathrm{mM}$ $\mathrm{NH}_{4} \mathrm{Ac}(50 / 50, v / v)$ was finally selected as the optimum sheath liquid.

The sheath liquid flow rate is another important parameter affecting the effectiveness of the ionization procedure and thus stability and sensitivity of MS detection. Here, the sheath liquid flow rate in the range of $2-10 \mu \mathrm{L} \mathrm{min}^{-1}$ was investigated. An $8 \mu \mathrm{L} \mathrm{min}{ }^{-1}$ sheath liquid flow rate was chosen as an optimum with respect to the highest $\mathrm{S} / \mathrm{N}$ ratio along with a stable electrospray and analytical signal.

Additional ESI parameters, responsible for an effective ionization procedure and stability of the analytical signal, were studied and optimized in the following ranges: nebulizing gas pressure (5-20 psi), drying gas temperature $\left(150-350^{\circ} \mathrm{C}\right)$, drying gas flow rate $\left(2-10 \mathrm{~L} \mathrm{~min}^{-1}\right)$, and capillary voltage $(3000-5500 \mathrm{~V})$. The highest triptorelin signal intensity and stability were obtained for nebulizing gas pressure $10 \mathrm{psi}$, drying gas temperature $300{ }^{\circ} \mathrm{C}$, drying gas flow rate $10 \mathrm{~L} \mathrm{~min}^{-1}$, and capillary voltage $5000 \mathrm{~V}$.

\subsubsection{MS/MS Step}

The optimization of MS/MS step included a chronological application of various triple quadrupole $(\mathrm{QqQ})$ operation modes, namely Scan mode, Selected Ion Monitoring (SIM) mode, Product Ion mode, and Multiple Reaction Monitoring (MRM) mode.

At first, the precursor ion of triptorelin $(m / z=656.5)$ was indicated in the Scan mode (Figure 1a). As it can be seen, the $m / z$ of the precursor ion represents double charged triptorelin ion. In the SIM mode, the fragmentor voltage in the range of 50-200 V was optimized. The highest intensity of the tiptorelin precursor ion was obtained when the fragmentor voltage was set at $160 \mathrm{~V}$.

Further, the collision cell energy in the range of $5-30 \mathrm{eV}$ was optimized in the Product Ion mode in order to obtain characteristic fragmentation spectrum of triptorelin. The optimum collision energy, with nitrogen as collision gas, was $20 \mathrm{eV}$. Two most abundant characteristic ions, i.e., quantifier (ion with the highest intensity, $\mathrm{m} / \mathrm{z}=328.3$ ) and qualifier $(m / z=249.0)$, were selected from the mass spectrum (Figure 1b). The selected product ions are in good agreement with the previous papers dealing with MS analyses of triptorelin [24,25].

Finally, the MRM mode was used for a highly reliable identification and quantification of the analyte. The following $\mathrm{m} / \mathrm{z}$ ion transitions were applied: $656.5 \rightarrow 328.3$ (quantification transition), $656.5 \rightarrow 249.0$ (identity confirmation transition). 
a)

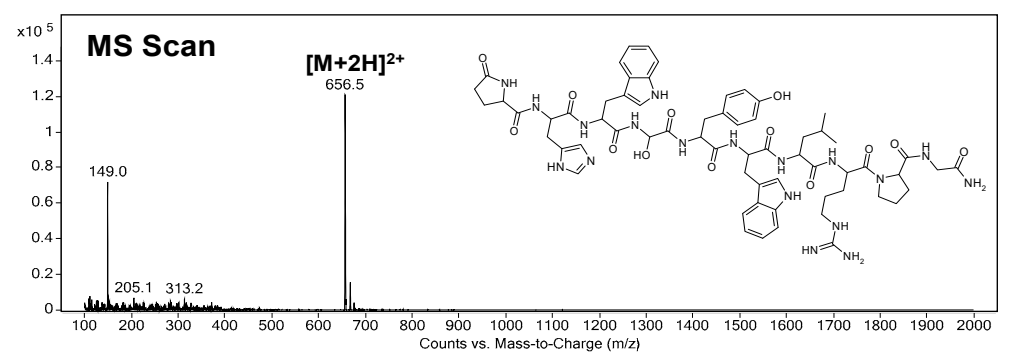

b)

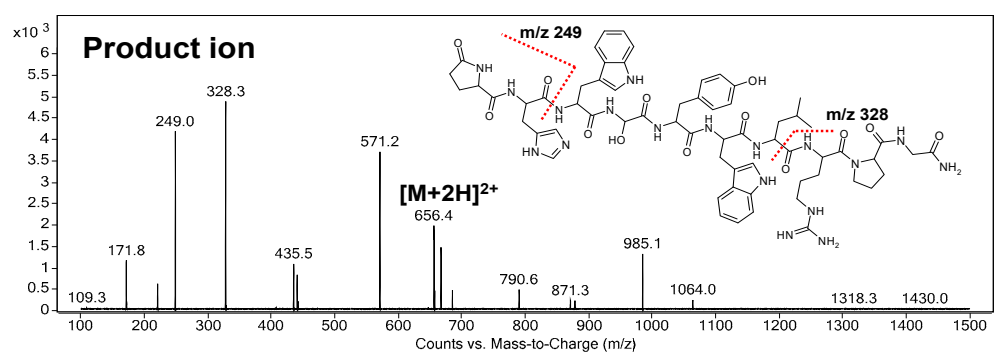

Figure 1. Representative parent ion (a) and product ion (b) triple quadrupole mass spectra of triptorelin. The spectral profiles indicate qualifier $(\mathrm{m} / \mathrm{z} 249.0)$ and quantifier $(\mathrm{m} / \mathrm{z} 328.3)$ product ions serving for unequivocal identification and quantification of triptorelin. The fragmentor voltage was set at $160 \mathrm{~V}$ and the collision energy was $20 \mathrm{eV}$.

\subsection{In-Capillary Sample Preconcentration and Improvement of the Sample Throughput \\ 3.3.1. Field-Enhanced Sample Injection (FESI)}

The above-mentioned previously published CE-MS methods dealing with the analysis of triptorelin suffered from relatively low sensitivity/high LODs and relatively poor peak area reproducibility (data in Table 2). In order to find conditions providing an enhancement of triptorelin LOD, we investigated and compared two approaches of the sample introduction into the separation capillary. The first one was represented by conventional hydrodynamic injection (50 mbar for $20 \mathrm{~s}$ ). With our optimized CE-MS method, the LOD value for triptorelin was predicted at $0.25 \mu \mathrm{g} \mathrm{mL}^{-1}$. It is a ca. 9-15 times improvement in the LOD value when comparing to the published methods. However, this value is still insufficient for biomedical analyses (such as therapeutic drug monitoring or pharmacokinetics study) where triptorelin at ultratrace concentration levels is present. Therefore, an in-capillary sample preconcentration strategy based on a field-enhanced sample injection (FESI) technique was investigated for triptorelin as an advanced sample injection alternative. The FESI procedure was carried out by the introduction of a short water plug (50 mbar for $5 \mathrm{~s}$ ) prior to the electrokinetic injection of the analyte. As it can be seen in Figure 2, the $\mathrm{S} / \mathrm{N}$ ratio of the triptorelin sample at $0.5 \mu \mathrm{g} \mathrm{mL} \mathrm{m}^{-1}$ concentration level increased significantly when applying FESI. The data summarized in Table 2 clearly demonstrate benefits of the optimized FESI-CE-MS method over the published CE-MS methods for triptorelin in terms of obtainable LOD and reproducibility of measurements.

Table 2. Comparison of selected validation parameters of the CE-MS methods for triptorelin in model water matrix.

\begin{tabular}{cccc}
\hline Injection & RSD $_{\text {area }}(\mathbf{\%})$ & LOD $\left(\boldsymbol{\mu g} \mathbf{~ m L}^{-\mathbf{1}}\right)$ & Reference \\
\hline Hydrodynamical & 15 & 3.65 & {$[15]$} \\
Hydrodynamical & 33 & 2.25 & {$[16]$} \\
Hydrodynamical & 8.9 & 0.25 & This study \\
Electrokinetic & 5.5 & 0.005 & This study \\
\hline
\end{tabular}


a)

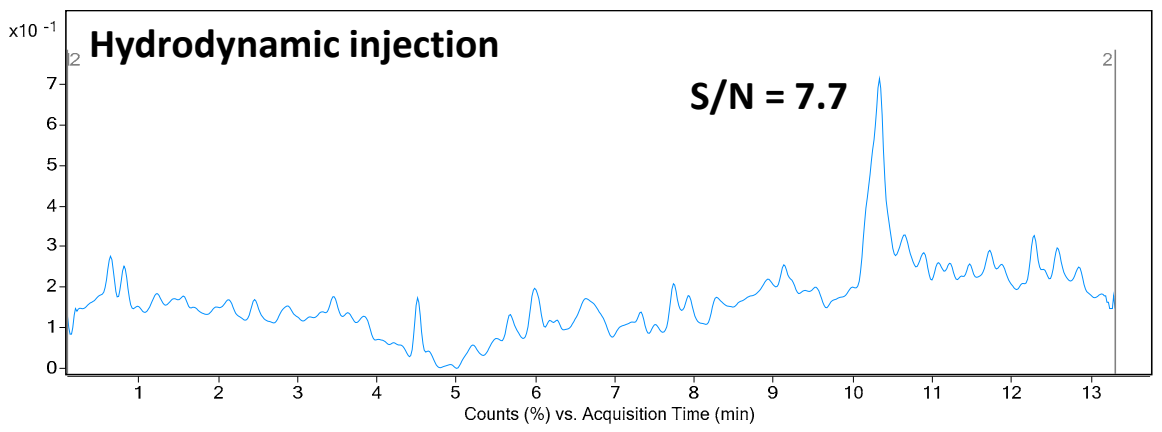

b)

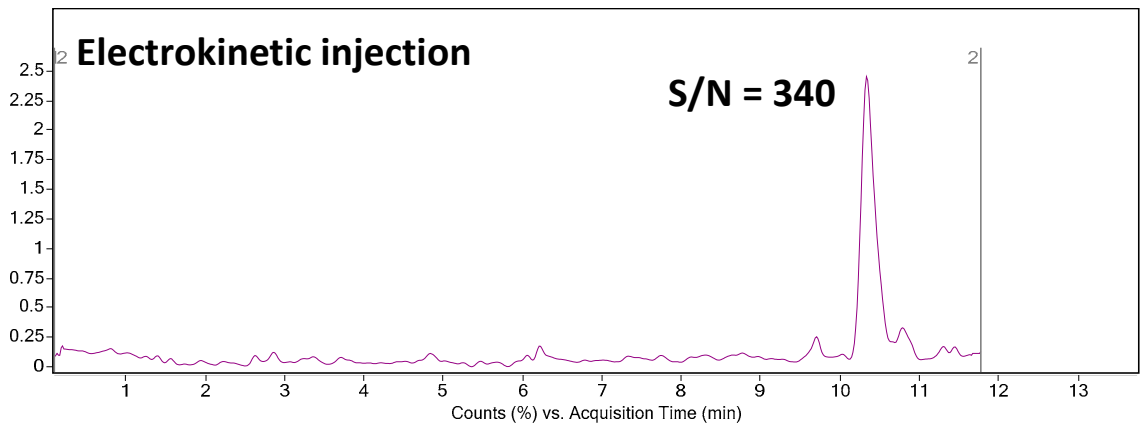

Figure 2. Effect of the CE injection mode (hydrodynamic vs. electrokinetic) on the analytical signal intensity. Concentration of triptorelin in the analyzed model sample was $0.5 \mu \mathrm{gL}^{-1}$. (a) Hydrodynamic injection was performed at $50 \mathrm{mbar}$ for $20 \mathrm{~s}$. (b) The electrokinetic injection (FESI) was performed at $10 \mathrm{kV}$ for $20 \mathrm{~s}$ after the hydrodynamic introduction of a short water plug (50 mbar for $100 \mathrm{~s}$ ) into the capillary. For other details of the CE-MS method see Section 2.

\subsubsection{Multisegment Injection (MSI)}

The development of modern analytical methods aimed to a routine use is faced not only with the demands on a high sensitivity but also an enhanced sample throughput. One of the possibilities how to improve the sample throughput in CE is a serial injection of multiple sample segments within a single capillary. The multisegment injection (MSI) strategy performed in the CE-MS configuration has been predominantly applied in highthroughput metabolomics analyses [26-32]. Some papers deal with MSI-CE-MS also in drug quality control [33,34], screening of drugs of abuse [35], or peptide and protein analysis [36-38].

An MSI approach was implemented also in our analytical procedure. MSI is typically associated with the hydrodynamic injection of the samples. Here, we investigated the possibility to combine an in-capillary FESI preconcentration (based on electrokinetic injection of the sample) with a MSI procedure. The proposed MSI/FESI strategy was tested by three serial injections of the triptorelin model samples (prepared in water matrix). A baseline separation of three triptorelin peaks (corresponding to preconcentrated triptorelin zones migrating within three segments) was achieved when a short plug of the BGE (corresponding to hydrodynamic injection at $50 \mathrm{mbar}$ for $100 \mathrm{~s}$ ) was introduced into the CE capillary between each electrokinetic injection of the sample (i.e., FESI). The whole MSI/FESI-CE-MS analysis of three samples injected in one run was completed within $11 \mathrm{~min}$, which corresponded to the analysis time of CE-MS with the conventional hydrodynamic injection of one sample. Thus, the presented data clearly demonstrated a 3-times higher sample throughput plus 50-times lower LOD for triptorelin with the proposed MSI/FESI-CE-MS method in comparison with the same CE-MS method employing conventional hydrodynamic injection.

\subsection{Method Validation}

The optimized MSI/FESI-CE-MS method was validated according to the ICH Q2(R1) and FDA guidelines [39,40]. Validation characteristics such as specificity, linearity, range, 
accuracy, precision, limit of detection (LOD), limit of quantitation (LOQ), and robustness were investigated. Measurements were carried out in water and plasma matrices. The evaluated validation parameters are summarized in Tables 3 and 4 and discussed in the text below.

Table 3. Operation and calibration parameters of the MSI/FESI-CE-MS/MS method for determination of triptorelin in model water and plasma samples.

\begin{tabular}{ccc}
\hline Parameter & Water & Plasma \\
\hline $\mathrm{t}_{\mathrm{m}}(\mathrm{min})$ & 10.53 & 14.54 \\
$\mathrm{RSD}_{\mathrm{tm}}(\%), n=6$ & 0.24 & 0.99 \\
$\mathrm{RSD}_{\text {area }}(\%), n=6$ & 7.61 & 11.01 \\
$\mathrm{a}($ counts $)$ & 27.98 & 97.88 \\
$\mathrm{SD}_{\mathrm{a}}, n=6$ & 1.12 & 11.99 \\
$\mathrm{~b}($ counts.ng mL & $-1)$ & 171.78 \\
$\mathrm{SD}_{\mathrm{b}}, n=6$ & 238.01 & 4.65 \\
$\mathrm{r}^{2}$ & 2.52 & 0.985 \\
LOD $\left(\mathrm{ng} \cdot \mathrm{mL}^{-1}\right)$ & 0.992 & 25 \\
LOQ $\left(\mathrm{ng} \cdot \mathrm{mL}^{-1}\right)$ & 5 & 50 \\
$N$ & 10 & 36956
\end{tabular}

$\mathrm{t}_{\mathrm{m}}$-migration time, $\mathrm{RSD}_{\mathrm{tm}}$-relative standard deviation of migration time, $\mathrm{RSD}_{\text {area }}$-relative standard deviation of peak area, a-intercept of the calibration curve, $\mathrm{b}$ - slope of the calibration curve, $\mathrm{SD}_{\mathrm{a}}$ - standard deviation of intercept, $\mathrm{SD}_{\mathrm{b}}$ - standard deviation of slope, $\mathrm{LOD}$-limit of detection, $\mathrm{LOQ}$-limit of quantification, $\mathrm{N}$ separation efficiency. Separation efficiency $(N)$ was calculated according to the equation $N=5.545 \times\left(t_{m} / w_{1 / 2}\right)^{2}$. The separation efficiency was calculated for the analyte at its LOQ level.

Table 4. Accuracy and precision of the CE-MS/MS method for triptorelin in water/saline and plasma QC samples.

\begin{tabular}{cccccccc}
\hline & & \multicolumn{2}{c}{$\begin{array}{c}\text { Found }(\mu \mathrm{g} \\
\left.\mathbf{m L}^{-1}\right)\end{array}$} & \multicolumn{2}{c}{ RSD (\%) } & \multicolumn{2}{c}{ RE (\%) } \\
\cline { 3 - 8 } Mominal $\left(\mu \mathbf{~ m L}^{-1}\right)$ & Water & Plasma & Water & Plasma & Water & Plasma \\
\cline { 3 - 8 } & 0.01 & 0.01 & - & 3.6 & - & -19.0 & - \\
& 0.05 & 0.04 & 0.04 & 5.6 & 5.6 & -10.0 & -6.1 \\
Intraday, $n=6$ & 0.1 & 0.11 & - & 9.4 & - & 9.0 & - \\
& 0.5 & 0.47 & - & 6.4 & - & -5.8 & - \\
& 1 & 0.95 & 0.93 & 2.5 & 4.8 & -4.6 & -7.5 \\
& 2 & 1.95 & - & 2.8 & - & -2.5 & - \\
& 5 & 5.24 & - & 5.5 & - & 4.8 & - \\
& 10 & 9.72 & 10.25 & 1.5 & 5.5 & -2.8 & 2.5 \\
\hline \multirow{2}{*}{ Interday, $n=6$} & 0.01 & 0.01 & - & 4.2 & - & -19.8 & - \\
& 0.05 & 0.04 & 0.04 & 4.4 & 15.4 & -14.2 & -6.1 \\
& 0.1 & 0.11 & - & 11.9 & - & 9.3 & - \\
& 0.5 & 0.50 & - & 8.8 & - & -0.1 & - \\
& 1 & 0.99 & 0.94 & 6.1 & 11.9 & -1.5 & -6.4 \\
& 2 & 1.93 & - & 4.0 & - & -3.5 & - \\
& 5 & 5.47 & - & 5.3 & - & 9.4 & - \\
& 10 & 9.61 & 9.66 & 2.3 & 11.4 & -3.9 & -3.4 \\
\hline
\end{tabular}

RSD—relative standard deviation, RE - relative error

Specificity, as the ability to assess unequivocally the analyte in the presence of other sample constituents, was demonstrated by the analysis of a blank saline solution and blank plasma spiked with the triptorelin standard at the LOQ concentration level. The sample matrices were chosen with respect to the intended application of the method. The results were compared with the data obtained from the analysis of corresponding non-spiked matrices. Thanks to a high orthogonality of the MSI/FESI-CE-MS/MS method (operating in MRM mode of MS/MS), no interfering compounds with the triptorelin peak at its migration time were observed in both saline and plasma matrices. 
The calibration curves were established from eight calibration standards in the range of $0.01-10 \mu \mathrm{g} \mathrm{mL}^{-1}$ in model water samples and in the range of $0.05-10 \mu \mathrm{g} \mathrm{mL}^{-1}$ in pooled plasma samples. The calibration curves were expressed by the equation $y=b x+a$, where $b$ represents slope and a represents intercept of the calibration line (for the data see Table 3). The parameters of the calibration lines were calculated with the use of Microsoft Excel 2007 (Microsoft Corporation, Redmond, WA, USA). Appropriate linearity $\left(\mathrm{r}^{2}>0.99\right)$ in the range over two decadic orders was obtained for both matrices using the MSI/FESI-CE-MS method. The regression analysis indicated no statistical significance of the intercepts.

The LOD and LOQ values were calculated from the CE-MS profiles (of model water and plasma samples) as the signal-to-noise ratios $(\mathrm{S} / \mathrm{N})$ which should be 3:1 and 10:1, respectively. The predicted LOD values were 0.005 and $0.025 \mu \mathrm{g} \mathrm{mL}^{-1}$ in water and plasma matrices, respectively. When comparing with the literature, it represents the lowest level which was obtained for triptorelin in water matrix and the only LOD value determined and published for plasma by CE-MS methods. In comparison to the previously published CE-MS methods (in Table 2), a 450-750-times improvement of this parameter was reached. Illustrative records obtained from the MSI/FESI-CE-MS analysis of triptorelin at LOQ concentration levels in water and plasma are present in Figure 3.

\section{a)}

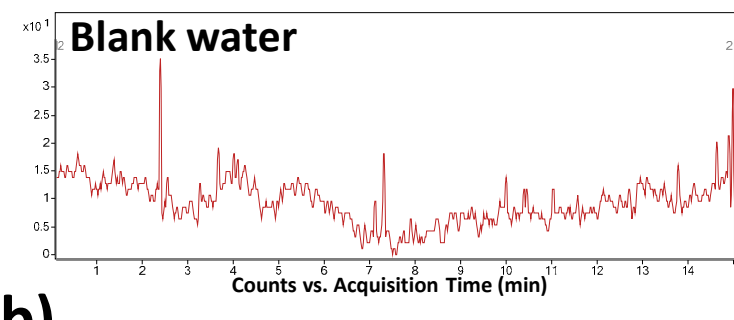

b)

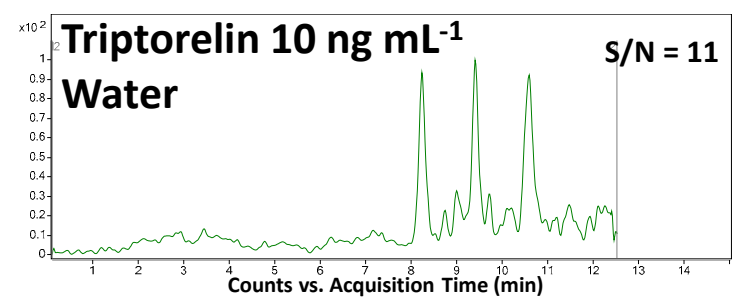

c)
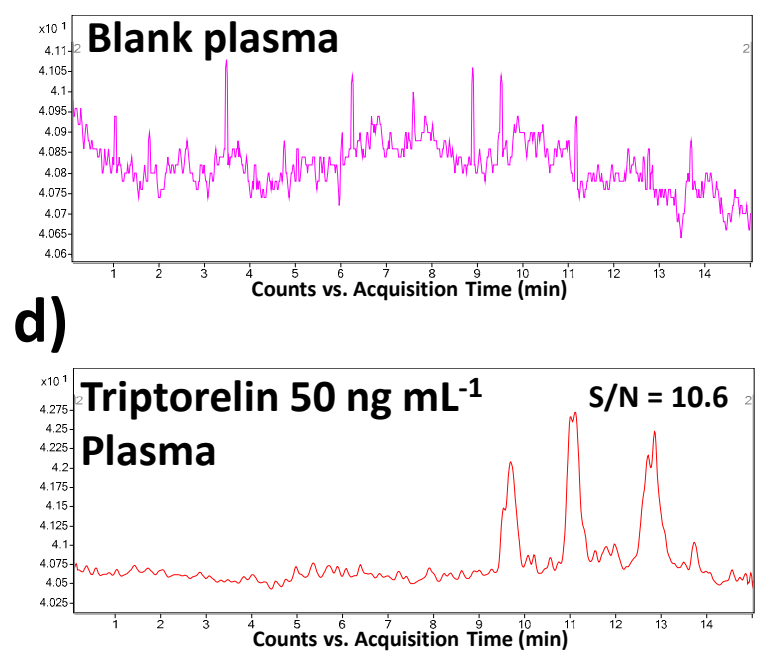

Figure 3. Representative multiple reaction monitoring (MRM) records obtained from the MSI/FESI-CE-MS analysis of (a) blank water (saline) sample, (b) triptorelin at the LOQ concentration level $\left(10 \mathrm{ng} \mathrm{mL}^{-1}\right)$ in water, (c) blank plasma sample, and (d) triptorelin at the LOQ concentration level $\left(50 \mathrm{ng} \mathrm{mL}^{-1}\right)$ in plasma. The records were obtained for the $m / z$ transition $656.5 \rightarrow 328.3$. For other details of the CE-MS method see Section 2.

A series of quality control (QC) triptorelin samples prepared in water and plasma matrices in the calibration range of $0.01-10 \mu \mathrm{g} \mathrm{mL}^{-1}$ was used to evaluate precision and accuracy of the developed MSI/FESI-CE-MS method (see data in Table 4). The precision was investigated as intra- and interday repeatability. The intraday precision was determined by measuring the samples (three consecutive runs) within one day. The interday precision was evaluated by repeated analysis of the samples (three replicates per day) for 4 days. The intraday precision (\%RSD) ranged in the interval of $1.5-9.4 \%$ (water matrix) and 4.8-5.6\% (plasma matrix). The corresponding accuracy (expressed as \% relative error) was within the interval of $81-109 \%$ (water matrix) and $92.5-102.5 \%$ (plasma matrix). For the interday experiments, the precision varied from $2.3 \%$ to $11.9 \%$ (water matrix) and from $11.4 \%$ to $15.4 \%$ (plasma matrix) and the accuracy was within $80.2-109.4 \%$ (water matrix) and 93.6-96.6\% (plasma matrix). The acceptation ICH and FDA criteria for precision and accuracy were accomplished so that the developed MSI/FESI-CE-MS method provides reliable quantification of triptorelin. 
The stability of triptorelin in pooled QC plasma samples was examined after storing them for $24 \mathrm{~h}$ in CE autosampler (short-term stability) and after performing three complete freeze and thaw cycles from $-20{ }^{\circ} \mathrm{C}$ to $+20{ }^{\circ} \mathrm{C}$ (freeze-to-thaw stability). The measured concentrations of triptorelin were in the range of $80.6-95.2 \%$ compared to the initial concentrations (Table 5).

Table 5. Stability testing of triptorelin in plasma QC samples.

\begin{tabular}{ccccccc}
\hline & \multicolumn{3}{c}{ Autosampler Stability } & \multicolumn{3}{c}{ Freeze-to-Thaw Stability } \\
\hline & Low & Medium & High & Low & Medium & High \\
\hline Nominal $\left(\mu \mathrm{g} \mathrm{mL}^{-1}\right)$ & 0.05 & 1 & 10 & 0.05 & 1 & 10 \\
Found $\left(\mu \mathrm{gL}^{-1}\right)$ & 0.04 & 0.95 & 9.39 & 0.04 & 0.86 & 9.21 \\
Accuracy $\left(\mathrm{RE}^{\circ}\right)$ & -18.2 & -4.8 & -6.1 & -19.4 & -13.9 & -7.9 \\
\hline
\end{tabular}

The suitability and reliability of the developed method for the demanded goal was also proven as robustness. Small and deliberate variations in method parameters, here variation of $\mathrm{pH}$ ( \pm 0.1 unit) and BGE concentration $( \pm 1 \mathrm{mM})$ were tested. No significant differences from the original (optimum) conditions were observed, the fluctuations of triptorelin migration time and peak area did not exceed 1\%. Therefore, the optimized method is robust enough for its practical routine use.

\subsection{Method Application}

The optimized and validated MSI/FESI-CE-MS method was finally applied for quantitation of triptorelin in real pharmaceutical and biological matrices.

As a pharmaceutical sample, a commercial drug Diphereline ${ }^{\circledR} 0.1 \mathrm{mg}$ (powder for injection) was analyzed. No extensive sample preparation before the analysis was necessary. A simple dilution with demineralized water was sufficient for this purpose. An illustrative record obtained from the analysis of a 100-times diluted drug dose is presented in Figure 4a. The declared content of triptorelin in the commercially available drug was $100 \mu \mathrm{g}$. The content of triptorelin determined by the proposed MSI/FESI-CE-MS method in three batches of Diphereline ${ }^{\circledR}$ ranged in the interval of $97.67-101.18 \mu \mathrm{g}$, which was in good agreement with the value declared by the manufacturer. An excellent reproducibility of the measurements of pharmaceutical samples was demonstrated by the \%RSD value which did not exceed $2.3 \%(n=6)$.

The application potential of the MSI/FESI-CE-MS method was demonstrated also via analysis of spiked human plasma samples at $0.1 \mu \mathrm{g} \mathrm{mL} \mathrm{m}^{-1}$ final concentration level of triptorelin (within the interval of triptorelin plasma levels in pharmacokinetics studies [41,42]). The preparation of model plasma sample was very simple. It included only protein precipitation (sample/acetonitrile with $0.1 \% \mathrm{HFo}, v / v=1: 3$ ) followed by centrifugation of the precipitated sample $(13000 \times g$ for $10 \mathrm{~min})$. The supernatant was directly injected. Ten spiked plasma samples (obtained from five healthy individuals) were analyzed in order to demonstrate an influence of the matrix variability on the fluctuation of electrokinetic injection and, by that, determined concentration of triptorelin. An illustrative record obtained from the analysis of triptorelin in a model plasma sample is presented in Figure $4 \mathrm{~b}$. Fluctuations of the concentration of triptorelin determined in ten different plasma samples ranged in the interval of $9.5-11.5 \%$. Hence, the electrokinetic injection was demonstrated to be a highly reliable injection tool for triptorelin when combined with the MSI/FESI-CE-MS analysis method. The recovery (calculated as peak areas ratio of the analyte in the spiked pooled plasma sample with those measured at the equivalent concentration in a reference water matrix) of triptorelin from the pooled plasma sample, prepared by equimolar mixing of five different plasma samples, was $90 \%$. These results clearly demonstrated usefulness of the developed method for highly effective and reliable monitoring of trace triptorelin in plasma samples. 


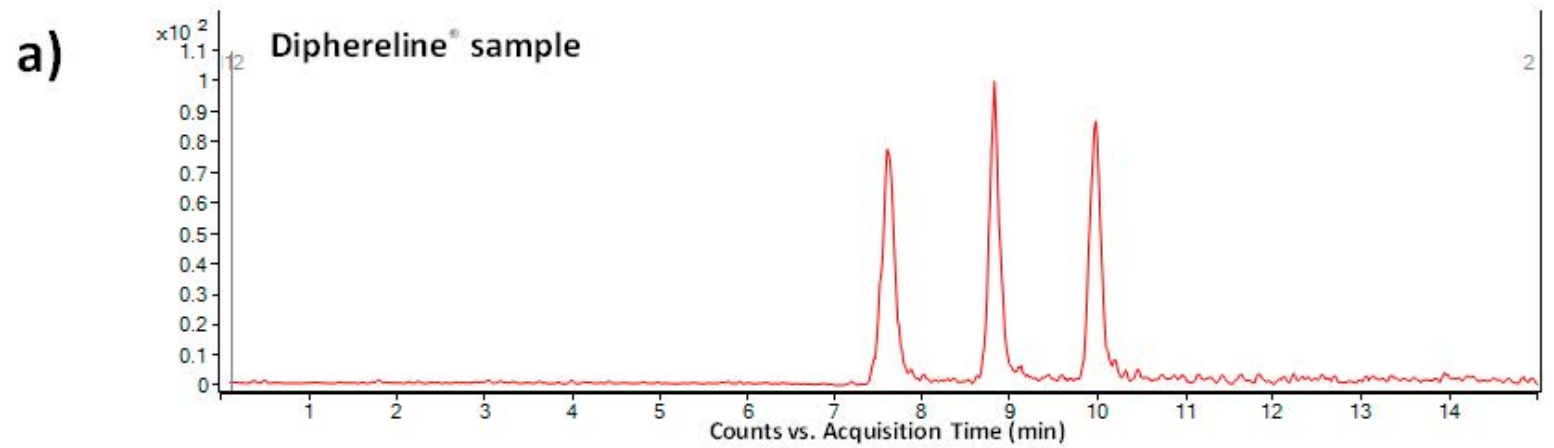

b)

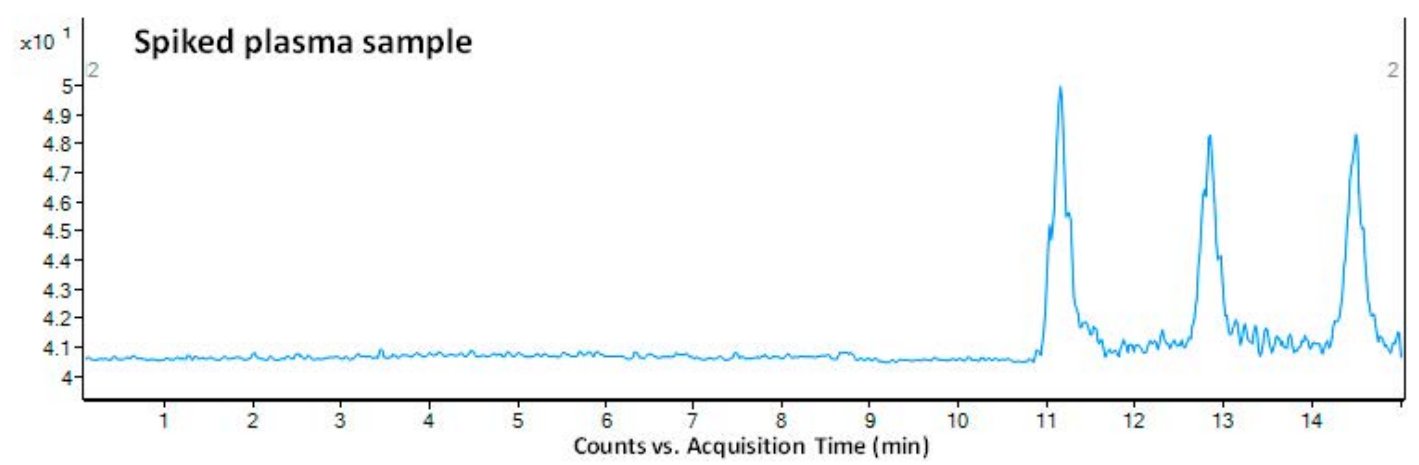

Figure 4. MSI-CE-MS analysis of (a) 100-times diluted pharmaceutical sample Diphereline ${ }^{\circledR} 0.1 \mathrm{mg}$ (powder for injection), and (b) plasma sample spiked with triptorelin standard at $0.1 \mu \mathrm{g} \mathrm{mL}^{-1}$ concentration level. The records were obtained for the $m / z$ transition $656.5 \rightarrow 328.3$. For more details of the CE-MS method see Section 2.

\subsection{Comparison of Methods for Triptorelin Analysis in Biological Samples}

Table 6 provides a summary of chromatographic and electrophoretic methods used for determination of triptorelin in biological samples, i.e., plasma, serum, and urine. Determination of triptorelin has been typically performed with the use of liquid chromatography (LC) coupled with MS [25,42-47] or UV detection [48,49]. Actually, the only CE method developed for biological samples is this one presented in our work. Although the published LC procedures provided lower LOD values for triptorelin in plasma $\left(0.006-6 \mathrm{ng} . \mathrm{mL}^{-1}\right)$ than our CE method $\left(25 \mathrm{ng} \mathrm{mL}^{-1}\right)$, they needed an external sample preparation procedure (extraction) to be used for the selectivity and sensitivity enhancement. Thus, the developed CE-MS/MS method can be an advantageous alternative to the established LC-MS/MS approaches in terms of simplicity and cost. In addition, the LOD value obtainable by means of the developed CE-MS/MS method is more than suitable for investigating the first phases of triptorelin pharmacokinetics studies.

Table 6. A summary of chromatographic and electrophoretic methods.

\begin{tabular}{|c|c|c|c|c|c|c|}
\hline Method. & Study & Matrix & Sample preparation & $t(\min )$ & LOD (ng mL $L^{-1}$ ) & Ref. \\
\hline LC-MS/MS & $\begin{array}{c}\text { Pharmacokinetic } \\
\text { study in rat }\end{array}$ & Plasma & $\begin{array}{l}\text { Protein precipitation, } \\
\text { solid phase extraction }\end{array}$ & $\sim 14$ & 6 & [42] \\
\hline LC-MS/MS & $\begin{array}{c}\text { Pharmacokinetic } \\
\text { study in beagle dog }\end{array}$ & Plasma & $\begin{array}{l}\text { Protein precipitation, } \\
\text { solid phase extraction }\end{array}$ & $\sim 14$ & 0.006 & [43] \\
\hline UHPLC-MS/MS & $\begin{array}{c}\text { Monitoring of } \\
\text { chemical castration }\end{array}$ & Serum & $\begin{array}{l}\text { Protein precipitation, } \\
\text { solid phase extraction }\end{array}$ & 12 & 0.25 & [44] \\
\hline LC-MS/MS/MS & $\begin{array}{c}\text { Pharmacokinetic } \\
\text { study in rat }\end{array}$ & Plasma & $\begin{array}{c}\text { Protein precipitation, } \\
\text { micro-solid } \\
\text { phase extraction }\end{array}$ & 5 & 0.006 & [45] \\
\hline
\end{tabular}


Table 6. Cont.

\begin{tabular}{|c|c|c|c|c|c|c|}
\hline Method. & Study & Matrix & Sample preparation & $t(\min )$ & LOD (ng mL $\mathbf{~}^{-1}$ ) & Ref. \\
\hline LC-MS/MS & $\begin{array}{l}\text { Model study } \\
\text { for antidoping }\end{array}$ & Urine & Centrifugation & 15 & 0.25 & [46] \\
\hline LC-MS/MS & $\begin{array}{c}\text { Pharmacokinetic } \\
\text { study in rat }\end{array}$ & Plasma & $\begin{array}{l}\text { Protein precipitation, } \\
\text { solid phase extraction }\end{array}$ & 6 & 0.006 & [25] \\
\hline LC-MS/MS & $\begin{array}{c}\text { Pharmacokinetic } \\
\text { study in rat }\end{array}$ & Plasma & $\begin{array}{l}\text { Protein precipitation, } \\
\text { solid phase extraction }\end{array}$ & 3 & 0.3 & [47] \\
\hline LC-UV & $\begin{array}{l}\text { Pharmacokinetic } \\
\text { study in rabbit }\end{array}$ & Plasma & $\begin{array}{l}\text { Dilution, } \\
\text { electromembrane } \\
\text { extraction }\end{array}$ & 12 & 0.15 & {$[48]$} \\
\hline LC-UV & $\begin{array}{l}\text { Model study } \\
\text { of spiked } \\
\text { human plasma }\end{array}$ & Plasma & $\begin{array}{c}\text { Dilution, } \\
\text { electromembrane } \\
\text { extraction }\end{array}$ & 40 & 0.6 & [49] \\
\hline CE-MS/MS & $\begin{array}{l}\text { Model study } \\
\text { of spiked } \\
\text { human plasma }\end{array}$ & Plasma & Protein precipitation & 15 & 25 & This study \\
\hline
\end{tabular}

UHPLC - ultra high-performance liquid chromatography, MS/MS/MS - multiple mass spectrometry.

\section{Conclusions}

In the present study, a novel MSI/FESI-CE-MS method for quantitative analysis of triptorelin in pharmaceutical and biological samples was developed and validated. For the first time, the FESI in-capillary preconcentration procedure was implemented in the MSI strategy resulting in a considerable enhancement of both sensitivity and sample throughput. The method was applied for quality control of the commercial drug Diphereline ${ }^{\circledR} 0.1 \mathrm{mg}$. It was also successfully tested for the analysis of trace triptorelin in spiked plasma samples obtaining reliable analytical data in such variable multicomponent matrices.

The complex validation procedure proved that the developed analytical strategy could be advantageously implemented in the field of quality control of triptorelin in pharmaceutical samples. Although the samples from patients treated with triptorelin were not available in this study, the validation data obtained from the analysis of a series of different plasma samples (obtained from healthy individuals) clearly demonstrated potentialities of the developed method for a routine monitoring of trace concentration levels of triptorelin in clinical samples (such as therapeutic drug monitoring, pharmacokinetic studies, compliance testing, etc.).

Author Contributions: Conceptualization, methodology, validation, investigation, data curation, writing - original draft, J.P.; investigation, data curation, M.M., A.H. and O.Š.; investigation, validation, data curation, I.Č. and P.M. (Petra Majerová); conceptualization, methodology, supervision, writing-review and editing, P.M. (Peter Mikuš). All authors have read and agreed to the published version of the manuscript.

Funding: The work was supported by the projects VEGA 1/0463/18, KEGA 027UK-4/2020, APVV15-0585, CRP/19/016, VEGA 2/0150/19, APVV-18-0302 and FaF UK/3/2021 and carried out in the Toxicological and Antidoping Center at the Faculty of Pharmacy Comenius University.

Institutional Review Board Statement: The study was conducted according to the guidelines of the Declaration of Helsinki and approved by the Ethical Committee of National Oncology Institute, Bratislava, Slovakia (protocol IZLO-1).

Informed Consent Statement: Not applicable.

Data Availability Statement: Data is contained within the article.

Conflicts of Interest: The authors declare no conflict of interest. 


\section{References}

1. Mahfouda, S.; Moore, J.K.; Siafarikas, A.; Zepf, F.D.; Lin, A. Puberty suppression in transgender children and adolescents. Lancet Diabetes Endo. 2017, 5, 816-826. [CrossRef]

2. WADA. The 2020 Prohibited List. Available online: https://www.wada-ama.org/sites/default/files/wada_2020_english_ prohibited_list_0.pdf (accessed on 19 November 2019).

3. Li, W.; Zhang, J.; Tse, F.L.S. Handbook of LC-MS Bioanalysis, 1th ed.; John Wiley \& Sons: Hoboken, NJ, USA, 2013.

4. Van Andel, L.; Rosing, H.; Schellens, J.H.M.; Beijnen, J.H. Review of chromatographic bioanalytical assays for the quantitative determination of marine-derived drugs for cancer treatment. Mar. Drugs 2018, 16, 246. [CrossRef] [PubMed]

5. Kočová Vlčková, H.; Pilařová, V.; Svobodová, P.; Plíšek, J.; Švec, F.; Nováková, L. Current stage of bioanalytical chromatography in clinical analysis. Analyst 2018, 143, 1305-1325. [CrossRef] [PubMed]

6. Wong, A.L.-A.; Xiang, X.; Ong, P.S.; Mitchell, E.Q.Y.; Syn, N.; Wee, I.; Kumar, A.P.; Yong, W.P.; Sethi, G.; Goh, B.C.; et al. A review on liquid chromatography-tandem mass spectrometry methods for rapid quantification of oncology drugs. Pharmaceutics 2018, 10, 221. [CrossRef] [PubMed]

7. Zhu, P.H.; Bowden, P.; Du, Z.; Marshall, J.G. Mass spectrometry of peptides and proteins from human blood. Mass Spectrom. Rev. 2011, 30, 685-732. [CrossRef]

8. Zemenova, J.; Sykora, D.; Adamkova, H.; Maletinska, L.; Elbert, T.; Marek, A.; Blechova, M. Novel approach to determine ghrelin analogs by liquid chromatography with mass spectrometry using a monolithic column. J. Sep. Sci. 2017, 40, 1032-1039. [CrossRef]

9. Zhang, Z.; Li, R.; Liu, S.; Yin, L.; Xu, T.; Fawcett, J.P.; Gu, J. Liquid chromatography tandem mass spectrometry with triple stage fragmentation for highly selective analysis and pharmacokinetics of alarelin in rat plasma. J. Sep. Sci. 2019, 42, 3033-3040. [CrossRef]

10. Piestansky, J.; Barath, P.; Majerova, P.; Galba, J.; Mikus, P.; Kovacech, B.; Kovac, A. A simple and rapid LC-MS/MS and CE-MS/MS analytical strategy for the determination of therapeutic peptides in modern immunotherapeutics and biopharmaceutics. J. Pharm. Biomed. Anal. 2020, 189, 113449. [CrossRef]

11. Stolz, A.; Jooß, K.; Höcker, O.; Römer, J.; Schlecht, J.; Neusüß, C. Recent advances in capillary electrophoresis-mass spectrometry: Instrumentation, methodology and applications. Electrophoresis 2019, 40, 79-112. [CrossRef]

12. Voeten, R.L.C.; Ventouri, I.K.; Haselberg, R.; Somsen, G.W. Capillary electrophoresis: Trends and recent advances. Anal. Chem. 2018, 90, 1464-1481. [CrossRef]

13. Sanz-Nebot, V.; Benavente, F.; Toro, I.; Barbosa, J. Migration behaviour of therapeutic peptide hormones: Prediction of optimal separation by capillary electrophoresis. Electrophoresis 2001, 22, 4333-4340. [CrossRef]

14. Sanz-Nebot, V.; Benavente, F.; Toro, I.; Barbosa, J. Evaluation of chromatographic versus electrophoretic behaviour of a series of therapeutic peptide hormones. J. Chromatogr. A 2003, 985, 411-423. [CrossRef]

15. Sanz-Nebot, V.; Benavente, F.; Toro, I.; Barbosa, J. Capillary electrophoresis coupled to time of flight-mass spectrometry of therapeutic peptidehormones. Electrophoresis 2003, 24, 883-891. [CrossRef] [PubMed]

16. Sanz-Nebot, V.; Benavente, F.; Toro, I.; Barbosa, J. Comparison of sheathless and sheath-flow electrospray interfaces for the capillary electrophoresis-electrospray ionization-mass spectrometry analysis of peptides. Electrophoresis 2005, 26, 1457-1465. [CrossRef]

17. Progent, F.; Taverna, M.; Le Potier, I.; Gopée, F.; Ferrier, D. A study of the binding between polymers and peptides, using affinity capillary electrophoresis, applied to polymeric drug delivery systems. Electrophoresis 2002, 23, 938-944. [CrossRef]

18. Pantůčková, P.; Gebauer, P.; Boček, P.; Křivánková, L. Electrolyte systems for on-line CE-MS: Detection requirements and separation possibilities. Electrophoresis 2009, 30, 203-214. [CrossRef]

19. Ploch, M.; Bunz, S.-C.; Neusüß, C. Capillary electrophoresis/mass spectrometry relevant to pharmaceutical and biotechnological applications. Electrophoresis 2012, 33, 1517-1530.

20. Herrero, M.; Ibañez, E.; Cifuentes, A. Capillary electrophoresis-electrospray mass spectrometry in peptide analysis and peptidomics. Electrophoresis 2008, 29, 2148-2160. [CrossRef]

21. Scriba, G.K.E. Separation of peptides by capillary electrophoresis. In Capillary Electrophoresis. Methods in Molecular Biology, 1th ed.; Schmitt-Kopplin, P., Ed.; Humana Press: New York, NY, USA, 2016; pp. 365-391.

22. Gomes, F.P.; Yates III, J.R. Recent trends of capillary electrophoresis-mass spectrometry in proteomics research. Mass Spectrom. Rev. 2019, 38, 445-460. [CrossRef]

23. Klampf, C.K.; Himmelsbach, M. Sheath liquids in CE-MS: Role, parameters, and optimization. In Capillary Electrophoresis-Mass Spectrometry (CE-MS): Principles and Applications, 1th ed.; de Jong, G., Ed.; Wiley-VCH Verlag: Weinheim, Germany, 2016; pp. 41-63.

24. Mazzarino, M.; Calvaresi, V.; de la Torre, X.; Parrotta, G.; Sebastianelli, C.; Botrè, F. Development and validation of a liquid chromatography-mass spectrometry procedure after solid-phase extraction for detection of 19 doping peptides in human urine. Forensic Toxicol. 2015, 33, 321-337. [CrossRef]

25. Han, J.; Zhang, S.; Liu, W.; Leng, G.; Sun, K.; Li, Y.; Di, X. An analytical strategy to characterize the pharmacokinetics and pharmacodynamics of triptorelin in rats based on simultaneous LC-MS/MS analysis of triptorelin and endogenous testosterone in rat plasma. Anal. Bioanal. Chem. 2014, 406, 2457-2465. [CrossRef] [PubMed]

26. Kuehnbaum, N.L.; Kormendi, A.; Britz-McKibbin, P. Multisegment injection-capillary electrophoresis-mass spectrometry: A high-throughput platform for metabolomics with high data fidelity. Anal. Chem. 2013, 85, 10664-10669. [CrossRef] [PubMed] 
27. Kuehnbaum, N.L.; Gillen, J.B.; Kormendi, A.; Lam, K.P.; DiBattista, A.; Gibala, M.J.; Britz-McKibbin, P. Multiplexed separations for biomarker discovery in metabolomics: Elucidating adaptive responses to exercise training. Electrophoresis 2015, 36, $2226-2236$. [CrossRef]

28. Yamamoto, M.; Ly, R.; Gill, B.; Zhu, Y.; Moran-Mirabal, J.; Britz-McKibbin, P. Robust and High-Throughput Method for Anionic Metabolite Profiling: Preventing Polyimide Aminolysis and Capillary Breakages under Alkaline Conditions in Capillary Electrophoresis-Mass Spectrometry. Anal. Chem. 2016, 88, 10710-10719. [CrossRef]

29. Saoi, M.; Kennedy, K.M.; Gohir, W.; Sloboda, D.M.; Britz-McKibbin, P. Placental metabolomics for assessment of sex-specific differences in fetal development during normal gestion. Sci. Rep. 2020, 10, 9399. [CrossRef]

30. Shanmuganathan, M.; Kroezen, Z.; Gill, B.; Azab, S.; de Souza, R.J.; Teo, K.K.; Atkinson, S.; Subbaro, P.; Desai, D.; Anand, S.S.; et al. The maternal serum metabolome by multisegment injection-capillary electrophoresis-mass spectrometry: A high-throughput platform and standardized data workflow for large-scale epidemiological studies. Nat. Protoc. 2021, 16, 1966-1994. [CrossRef]

31. Yamamoto, M.; Shanmuganathan, M.; Hart, L.; Pai, N.; Britz-McKibbin, P. Urinary metabolites enable differential diagnosis and therapeutic monitoring of pediatric inflammatory bowel disease. Metabolites 2021, 11, 245. [CrossRef]

32. Igarashi, K.; Ota, S.; Kaneko, M.; Hirayama, A.; Enomoto, M.; Katumata, K.; Sugimoto, M.; Soga, T. High-throughput screening of salivary polyamine markers for discrimination of colorectal cancer by multisegment injection capillary electrophoresis tandem mass spectrometry. J. Chromatogr. A 2021, 1652, 462355. [CrossRef]

33. Staub, A.; Rudaz, S.; Veuthey, J.-L.; Schappler, J. Multiple injection technique for the determination and quantitation of insulin formulations by capillary electrophoresis and time-of-flight mass spectrometry. J. Chromatogr. A 2010, 1217, 8041-8047. [CrossRef]

34. Geiser, L.; Rudaz, S.; Veuthey, J.-L. Validation of capillary electrophoresis-mass spectrometry methods for the analysis of a pharmaceutical formulation. Electrophoresis 2003, 24, 3049-3056. [CrossRef]

35. DiBattista, A.; Rampersaud, D.; Lee, H.; Kim, M.; Britz-McKibbin, P. High Throughput Screening Method for Systematic Surveillance of Drugs of Abuse by Multisegment Injection-Capillary Electrophoresis-Mass Spectrometry. Anal. Chem. 2017, 89, 11853-11861. [CrossRef]

36. Boley, D.A.; Zhang, Z.; Dovichi, N.J. Multisegment injections improve peptide identification rates in capillary zone electrophoresisbased bottom-up proteomics. J. Chromatogr. A 2017, 1523, 123-126. [CrossRef] [PubMed]

37. Zhang, S.; Raedschelders, K.; Santos, M.; Van Eyk, J.E. Profiling B-Type Natriuretic Peptide Cleavage Peptidoforms in Human Plasma by Capillary Electrophoresis with Electrospray Ionization Mass Spectrometry. J. Proteome Res. 2017, 16, 4515-4522. [CrossRef]

38. Saoi, M.; Sasaki, K.; Sagawa, H.; Abe, K.; Kogiso, T.; Tokushige, K.; Hashimoto, E.; Ohashi, Y.; Britz-McKibbin, P. High Throughput Screening of Serum $\gamma$-Glutamyl Dipeptides for Risk Assessment of Nonalcoholic Steatohepatitis with Impaired Glutathione Salvage Pathway. J. Proteome Res. 2020, 19, 2689-2699. [CrossRef]

39. ICH Harmonised Tripartite Guideline: Validation of Analytical Procedures: Text and Methodology. Step 4 Version. European Medicines Agency, November 2005. Available online: http:/ /www.ich.org/cache/compo/276-254-1.html (accessed on 18 July 2021).

40. U.S. Department of Health and Human Services Food and Drug Administration, Center for Drug Evaluation and Research (CDER) Center for Veterinary Medicine (CVM). Bioanalytical Method Validation Guidance for Industry; U.S. FDA: Rockville, MD, USA, 2018.

41. Minkov, N.K.; Zozikov, B.I.; Yaneva, Z.; Uldry, P.A. A phase II trial with new triptorelin sustained release formulations in prostatic carcinoma. Int. Urol. Nephrol. 2001, 33, 379-383. [CrossRef]

42. Wang, J.; Kong, S.; Yan, J.; Jin, G.; Guo, Z.; Shen, A.; Xu, J.; Zhang, X.; Zou, L.; Liang, X. Hydrophilic interaction liquid chromatography-solid phase extraction directly combined with protein precipitation for the determination of triptorelin in plasma. J. Chromatogr. B 2014, 960, 214-221. [CrossRef]

43. Han, J.; Sun, J.; Sha, C.; Zhang, J.; Gai, Y.; Li, Y.; Liu, W. Quantitation of slow release triptorelin in beagle dog plasma by liquid chromatography-tandem mass spectrometry. J. Pharm. Biomed. Anal. 2012, 66, 334-338. [CrossRef] [PubMed]

44. Ko, D.-H.; Lee, K.; Jeon, S.-H.; Song, S.H.; Yun, Y.-M.; Chun, S.; Kim, H.S.; Kim, J.Y.; In, M.K.; Song, J. Simultaneous measurement of serum chemical castration agents and testosterone levels using ultra-performance liquid chromatography-tandem mass spectrometry. J. Anal. Toxicol. 2016, 40, 294-303. [CrossRef] [PubMed]

45. Ren, T.; Zhang, Z.; Fawcett, J.P.; Sun, D.; Gu, J. Micro-solid phase extraction and LC-MS(3) for the determination of triptorelin in rat plasma and application to a pharmacokinetic study. J. Pharm. Biomed. Anal. 2019, 166, 13-19. [CrossRef] [PubMed]

46. Thomas, A.; Görgens, C.; Guddat, S.; Thieme, D.; Dellanna, F.; Schänzer, W.; Thevis, M. Simplifying and expanding the screening for peptides $<2 \mathrm{kDa}$ by direct urine injection, liquid chromatography, and ion mobility mass spectrometry. J. Sep. Sci. 2016, 39, 333-341. [PubMed]

47. Forsback, A.-P.; Noppari, P.; Viljanen, J.; Mikkola, J.; Jokinen, M.; Leino, L.; Bjerregaard, S.; Borglin, C.; Halliday, J. Sustained invivo release of triptorelin acetate from a biodegradable silica depot: Comparison to Pamorelin ${ }^{\circledR}$ LA. Nanomaterials 2021, $11,1578$. [CrossRef] [PubMed]

48. Davarani, S.S.H.; Pourahadi, A.; Ghasemzadeh, P. Quantification of controlled release leuprolide and triptorelin in rabbit plasma using electromembrane extraction coupled with HPLC-UV. Electrophoresis 2019, 40, 1074-1081. [CrossRef] [PubMed]

49. Nojavan, S.; Bidarmanesh, T.; Mohammadi, A.; Yaripour, S. Electromembrane extraction of gonadotropin-releasing hormone agonists from plasma and wastewater samples. Electrophoresis 2016, 37, 826-833. [CrossRef] [PubMed] 